he has afforded us of investigating the cases under his charge.

Note.-The charts are divided into weeks. The continuous line shows the temperature, which was taken twice a day. The broken line shows the amount of agglutinins present.

\section{A CASE OF HYDROCELE OF THE SAC OF A FEMORAL HERNIA.}

BY DUNCAN MACARTNEY, M.A. EdIN., M.D. GlisG,, SURGHON TO THE GLASGOW CANCER HOSPITAL; ASSISTANT SURGEON TO TETK GIASGOW WESTERN INFIRMARY.

THE report of a case of this extremely rare condition under the care of Dr. F. C. H. Piggott by the house surgeon of Teignmouth Hospital, Mr. A. A. Bradburne, which was published in THE LANCET of July 15th, 1899, p. 157, forcibly reminds one of how rarities come under notice not singly but in small groups, to re-appear perhaps after a long interval. In surgical wards it is quite noticeable how groups of abdominal cases or strangulated herniæ may appear in a day and none appear again for a long time.

Three months ago I operated on a patient whose case is almost identical with that under the care of Dr. Piggott. It is within the experience of most of us that hernia in a child may be cured for a more or less prolonged period by the careful use of a well-fitting truss for two or three years, but I think that it is extremely rare to find such a condition cured in a patient of advanced years; least of all if the hernia is femoral.

My patient, a woman, aged 56 years, bad been the subject of femoral hernia first about six years ago. It was then reducible, she informed me. Her medical attendant at that time ordered her to wear a truss. This she did for more than four years and it was at the end of this period that she was placed under my care. When first seen by me she had considerable pain and redness of the skin over the part, the tissues being soft and atrophied by the pressure of the trusspad. The swelling, as usually found in femoral herniæ, along and below the line of Poupart's ligament, was quite characteristic ; but the hernia was irreducible now. After a few days' rest in bed the local pain and redness passed away and she was allowed to get up, discarding the truss. Several times since then I had occasion to examine the part and found it in statu quo antea. About three months ago she had occasion to stand at a meeting of some kind for several hours. While standing there she felt something give way in the groin and pain almost at once set in. With some difficulty she got home and went to bed. I was sent for and on examination found that the hernial tumour was larger, distinctly painful to the touch, and irreducible. There was no vomiting, the bowels had just moved naturally, the temperature was normal, her face was not like that of a patient with intestinal obstruction, and the pain was confined to the tumour. Keeping the possibility of strangulation in mind I had the parts well fomented for several days. The pain became less but the swelling and irreducibility still persisted. I recommended operation, which was also advised by Dr. Hector Cameron, who was called in in consultation.

The operation was done on June 1st. Chloroform was administered by Dr. J. L. Carstairs. An incision was made over the tumour from Poupart's ligament downwards and outwards along its whole length. On getting down to the mass I found a large piece of omentum firmly matted together and slightly changed in colour and consistence, being yellower and firmer with less blood-supply than normal; in size, about half of a man's fist and tapering up to a neck-like process which ended in the crural canal. There was no defined sac around the mass of fat, but on its inner side where it made for the ring there was a sac also tapering towards the crural ring the wall of which was quite the commonly met with hernial sac with serous straw-coloured fluid as contents. This sac was quite separated from the abdominal cavity. Neither finger nor probe could get into the ring, the crural canal being effectively plugged by what had been the neck of the sac and the part of omentum within the canal becoming consolidated and adhering to the surrounding tissue. I removed the whole mass after ligaturing with strong catgut at the ring and anchoring this stump to Poupart's and Gimbernat's ligaments. The bleeding was stopped. The wound was cleaned and sewn up with about 20 fishing-gut sutures. On cutting into the omentum removed there appeared a mass of recent blood-clot of the size of a large walnut. So the symptoins were explained: the truss had been worn lightly over the neck of the unreduced omental hernia or the omentum may have slipped down behind the truss. The steady pressure had obliterated the sac-neck and cured the hernia, leaving the omentum outside, which in the meantime united to the sac and the tissues in Scarpa's triangle and secured its blood-supply therefrom. The stress of prolonged standing had caused the rupture of a small vessel in the somewhat degenerated mass, forming a bæmatocele-hence the feeling of something giving way and the subsequent pain. The patient is now three months after operation taking a holiday down the Clyde.

My case seems to come under the category defined by Erichsen and quoted by Mr. Bradburne: "This disease must not be confounded with the accumulation of fluid in whatever quantity in strangulated hernix or in hernial sacs that communicate with the peritoneal capity. Its distinguishing feature is the accumulation of fluid in a part of the sac that has been cut off from all communication with the cavity of the peritoneum," and it is another proof of the advantage of keeping an open mind in operat. ing on hernia, whether strangulated or not. It is best never to have any definite expectations as to what you will find, for here, more than in any surgical operation, the unexpected oftenest happens.

Glasgow.

\section{GUAIACOL CARBONATE AND CREASOTE CARBONATE IN BRONCHITIS AND PNEUMONIA.}

\section{BY DR. R. SEIFERT.}

SINCE the first articles published by Dr. Hölscher and myself ${ }^{1}$ on the beneficial action of guaiacol carbonate (Duotal) in tuberculosis of the lungs, articles which were soon followed by those of Chaumier ${ }^{2}$ on the similar action of creasote carbonate (creasotal), our experiments bave been verified by many physicians of all countries. THE LANCEI has also during the last few years more than once published descriptions by me of important new experiments on this subject. ${ }^{2}$ The interesting discovery has now been made that the favourable action of duotal and creasotal is not only manifest in chronic diseases of the lungs but even in a still more obvious and characteristic manner in all acute diseases of the respiratory organs. According to the published statements of the French physicians, Dr. Cassoute and Dr. Corgier, pneumonia in all its complicated forms seems to have been deprived of all danger by the new method of treatment.

At the Pediatric Congress which was held at Marseilles last year Dr. Cassoute, physician-in-chief to the Marseilles hospitals, gave a brief preliminary notice of his new method for the treatment of pulmonary affections, and it has now been described in detail by Dr. Corgier in a pamphlet entitled, "The Treatment of Acute Broncho-Pulmonary Affections by Creasotal" (Montpellier, 1899). Dr. Cassoute's new method is distinguished by the certainty and rapidity of its curative effects not less than by its simplicity. All other medication with the exception of cardiac tonics, when such are indicated, is omitted; so also are all the usual adjurants in the treatment of these cases. At the very most packs are occasionally employed. The method consists in the continuous administration of fairly large doses of creasotal. In most cases a typical fall of temperature occurred during the first 24 hours of treatment, and if the creasotal was continued for a sufficiently long period of time the apyrexia was permanent. The temperature curve rose again, however, when the drug was discontinued before the auscultatory signs disappeared. Relapses and sequelæ, so frequently seen under other methods, were entirely absent. It is remarkable that even the most modern and exhaustive text-books, whilst they describe all possible methods of treatment of pneumonia and broncho-pneumonia, say nothing of the antiseptic

1 Berliner Klinische Wochenschrift, 1891.

The TNCHe

3 The Lancet, Nov. 14th, 1896, p. 1373, and April 2nd, 1898, p. 960. 
one, directed against the infection which is the cause of the disease. Creasotal has been proved to be by far the most suitable remedy for this purpose, possessing the powerful antiseptic action of creasote without its unpleasant and dangerous properties. By its means the entire body can be to a certain extent impregnated with creasote without any irritation of the digestive canal. The absorption of the drug by the intestine is a slow and continuous process, whilst its elimination takes place with rapidity. One hour after its ingestion creasote can be demonstrated in the soreath and urine. A continuous infiltration of creasote into the stream of the circulation can be effected by creasotal, andoubtedly influencing the life conditions of the pathogenic bacteria unfavourably. The action of creasotal is better in proportion as the infection for which it is employed is mild and recent. In the simpler cases, such as febrile bronchitis and broncho-pneumonia of medium severity, when creasotal is administered at the very beginning of the illness, the semperature falls at once and does not rise again, the auscultatory signs rapidly disappear and the patient's general condition quickly improves. In severer cases of pneumonia and broncho-pneumonia dependent on more virulent infection there occurs either a sudden fall of temperature, often followed next morning or next morning but one by a temporary rise, or there is a gradual defervescence. The entire course of the disease is noticeably shortened. In pseudo-lobar broncho-pneumonia the fall of temperature occurs even earlier than in the lobar forms. Of course, some cases of pneumonia in very advanced stages with extensive grey hepatisation do not react to the creasotal treatment. It should always be tried, however, since it is never possible to tell with certainty the degree of permeability of the lung. Expectorants, antipyretics, and even quinine are entirely omitted. The tolerance of the gastro-intestinal canal for creasotal was found to be complete. The appetite returned quickly. The shortening of the disease and the prevention of relapses must cause the chronic, creeping forms of the malady and its infectious sequelæ-tuberculosis, gangrene, cardiac and renal affections, \&c.- to become very rare. Creasotal is also efficacious in the fœild forms of the affections under consideration.

For adults Dr. Cassoute prescribes 10 grammes (two and a half drachms) in the first 24 hours in a mixture consisting of 10 grammes (two and a half drachms) of creasotal (Von Heyden), and 60 grammes (two ounces) of emulsion, to be taken in four doses. Or even more simply, he prescribes one ounce of creasotal (Von Heyden) and directs one teaspoonful (about five grammes, equal to one and a quarter drachms) to be taken morning and night in a cup of hot sugared milk. The doses for children are as follow :-Up to one year of age, from 025 to one gramme (from four to 15 grains) ; from one to four years of age, from one to three grammes (from one-quarter to three-quarters of a drachm) ; from four to six years of age, from three to four grammes (from three-quarters to one drachm); from six to 10 years of age, from four to five grammes (from one to one and \& quarter drachms). According to his prescription the quantity of creasotal, according to age as above, is mixed with 60 grammes (two ounces) of emulsion or syrup and taken daily in four divided doses. These doses can be increased without any danger. And since we can never tell in the beginning of the disease how virulent the infection may be a fairly large dose should be taken at first. Only when the temperature has sunk to the normal may the original dose be reduced to one half; the febrile curve must be carefully kept under observation, and the larger doses immediately resorted to when it begins to rise again. The administration of the creasotal must be stopped gradually, the dose being diminished in amount and given less frequently, until the last auscultatory sign has disappeared. Until the lesions are cicatrised a re-infection or a recrudescence of the virulence of the weakened bacteria is to be feared.

Creasotal has a remarkable power of reducing temperature in bronchitis and pneumonia. In simple bronchitis, especially in children, where there are no very alarming symptoms but only moderate fever in the evenings, varying from $38 \cdot 0^{\circ} \mathrm{C}$. $\left(1004^{\circ} \mathrm{F}\right.$.) to $39 \cdot 0^{\circ} \mathrm{C}$. $\left(102 \cdot 2^{\circ} \mathrm{F}\right.$.), and sonorous râles, creasotal works wonders. Since the action of the drug is the more energetic the milder the infection it is readily conceivable that we get especially rapid results in these benign cases. The evening temperature falls upon the day that the first dose of creasotal is administered. When the administration is continued for a few days, until the auscultatory signs have completely disappeared, the apyrexia is permanent and cure results. In pneumonia the temperature begins to fall a few hours after the administration of the first dose of creasotal ; apyrexia is reached in 24 or at the most in 48 hours. This crisis is observed under the classical treatment, and even under no treatment at all but since influenza has become endemic this classical temperature curve is observed with less and less frequency. When it does occur it is at the fifth day only, when the bronchial breathing has been present for two or three days; under the creasotal treatment it is observed on the first or second day of the disease, or even on the very day on which the bronchial breathing appears. Personal experimentation with creasotal readily proves that the constant fall in the temperature on the day of the first administration of the drug is no accidental matter. Anyone can verify the fact that the temperature rises again if the use of the drug is stopped too soon. This is an absolute proof of the efficacy of the remedy. The question as to whether it is possible to abort the disease in its very beginning is a difficult one to answer, for if the creasotal is given before the bronchial breathing has appeared the objection can always be raised that there was no pneumonia present at all. Similar benefit is obtained in broncho-pneumonia and pneumonia complicating influenza. As a general rule there is considerable elevation of temperature for several days in broncho-pneumonia; but in a number of cases of the disease the fever is remittent in character without real defervescence. In favourable cases the temperature slowly returns to the normal. Every sudden rise or fall of the thermometer is of bad omen. On the other hand, by the employment of creasotal in the pseudo-lobar form of pneumonic inflammation a rapid and permanent reduction of the temperature can be effected from the beginning. But in the serpiginous form (forme lobulaire disséminée), whilst complete apyrexia can be attained it is not always permanent, even when the administration of the creasotal is persisted in. Not infrequently the temperature rises on the next day or the next day but one, but never, especially in children, above $40^{\circ} \mathrm{C}$. $\left(104^{\circ} \mathrm{F}\right.$.) and a few tenths. The length of the febrile curve is noticeably shortened; it runs for eight days at the most and the febrile movement of convalescence never lasts for from two to three weeks with occasional exacerbations, as is so often the case under other treatment. In a word, it is quite sufficient to compare the fever curve of a case treated with creasotal with that of a bronchopreumonia to be convinced of the efficacy of the remedy.

Creasotal has a powerful action on the local pulmonary lesions. The smell of the patient's breath is sufficient evidence that it is to a large extent excreted by the lungs. The milder and more recent the auscultatory signs are the quicker and plainer is the action of the drug upon the local lung lesions. In catarrhal bronchitis the results of the administration of creasotal are visible day by day. In from two to three days, according to the intensity of the inflammation, the râles disappear, and the cough and expectoration diminish in amount. In the first stage of pneamonia, when hepatisation is still slight, the bronchial respiration disappears rapidly in a day or two and is immediately replaced by a "râle redux" of short duration. Even in advanced pneumonia creasotal is beneficial. It cannot, of course, immediately effect the repair of the lesions caused by the infiltration and the destruction of tissue, but it causes their rapid cicatrisation and prevents re-infection. The auscultatory signs always disappear more rapidly than usual under its administration. In broncho-pneumonia it occasionally happens that the auscultatory phenomena last for a considerable time after apyrexia has been attained. But they last a much shorter time than is the case with cases treated by other methods. We never observe those foci of moist râles which persist for an indefinite time and resist all manner of treatment. It is very important to note that when the auscultatory signs have disappeared and the creasotal has been taken for a sufficiently long time relapses never occur.

Under the influence of creasotal the patient's general condition improves rapidly pari passu with the fall in temperature. If the administration of the creasotal is continued for a certain time after apyrexia is attained the patient incurs no danger of relapse or of tuberculous infection, which so frequently finds a suitable field of growth prepared for it by the acute affections of the respiratory organs. Whilst 
creasote itself causes gastritis creasotal improves the condition of the gastro-intestinal tract. As soon as the temperature falls to the normal the tongue becomes clean and there is a vigorous appetite, so that when the patients happen to be children they crave for food as they do after recovery from typhoid fever. As soon as apyrexia appears full nourishment should be given and the creasotal should be discontinued. Neither cardiac affections nor albuminuria contra-indicate the employment of the drug.

From the large number of typical clinical histories collected by Dr. Cassoute, Dr. Corgier, and Dr. Platon from the Marseilles hospitals, the following few may be cited :-

CASE 1.- This patient was a child, three years old, who suffered from chronic bronchitis and was completely cured in three days after the administration of creasotal was begun. For a week the child had had a cough, increased evening temperature, restlessness at night, diminished appetite, and coated tongue. Auscultation showed scattered sonorous and moist râles. The treatment had been emetics, painting with tincture of iodine, benzoate of soda internaliy, and an enema of 0.25 gramme (four grains) of hydrochlorate of quinine at night. At the end of the week the child's condition was worse and the auscultatory signs had increased. Two grammes (half a drachm) of creasotal (Ton Heyden) were then given in four doses in emulsion in the 24 hours. On the evening of the same day the temperature fell and the night following was a better one. Three days later nothing could be found on auscultation and the cough had disappeared. The child took food and slept well and made a good recovery.

CASE 3.-The patient was a boy, nine years old, who suffered from bronchitis complicating influenza, with localised inflam. matory focus and threatening broncho-pneumonia. For the previous two days he had had high fever, headache, pains in the limbs, and cough. His temperature was $39 \cdot 2^{\circ} \mathrm{C}$. $\left(105 \cdot 6^{\circ} \mathrm{F}\right.$.) and bronchial râles were heard. He took four grammes (one drachm) of creasotal (Von Heyden) in four doses in the 24 hours. The first dose was administered at 9 P.M.: on the next morning at $10 \mathrm{~A} . \mathrm{M}$. the temperature was $37.2^{\circ} \mathrm{C} .\left(99^{\circ} \mathrm{F}\right.$.) and the râles were less numerous. The evening temperature was $37 \cdot 3^{\circ} \mathrm{C}$. $\left(99 \cdot 2^{\circ} \mathrm{F}\right.$.) and the bronchial râles had further diminished. On the next morning there was no fever and bronchial râles were absent. The child was eager for food and the tongue was clean. The dose of creasotal was diminished by one half. By the fourth day nothing could be found on auscultation and the child was pronounced cured. As a matter of precaution 0.5 gramme (eight grains) of creasotal was administered for two days longer. All the cases resembled this typical one. No blisters or emetics, no Kermes mineral, aconite, or opium were employed; only creasotal was used, and the patient made a rapid recovery without any complications.

CASE 5.-This patient was a child, three years old, suffering from pneumonia. The temperature was $39.9^{\circ} \mathrm{C}$. $\left(103.8^{\circ} \mathrm{H}.\right)$, and there had been chill, pain in the side, and vomiting for about 12 hours previously. Auscultation showed well-localised sounds. Two grammes (half a drachm) of creasotal were ordered at once, to be tiken in four doses during the 24 hours. The first dose was given at 9 A.M., the temperature being then $399^{\circ} \mathrm{C} .\left(103.8^{\circ} \mathrm{F}.\right)$. At $8 \mathrm{P} . \mathrm{M}$. the temperature was $38.5^{\circ} \mathrm{C} .\left(101.3^{\circ} \mathrm{F}\right.$. $)$; on the next morning it was $38.2^{\circ} \mathrm{C}$. $\left(100.8^{\circ} \mathrm{F}\right.$.) and at 7 P.M. on the same day it was $37.5^{\circ} \mathrm{C}$. $\left(99.5^{\circ} \mathrm{F}.\right)$. Apyrexia was thus attained within 48 hours of the beginning of the illness and 36 hours after the first dose of the creasotal. The cough and general condition improved rapidly, as did also the auscultatory signs. During the next few days the temperature remained at $37^{\circ} \mathrm{C}$. $\left(98 \cdot 6^{\circ} \mathrm{F}.\right)$. Being alarmed by the dark coloration of the urine the child's parents stopped the medicine. On the next morning there was a violent chill again, witb pain in the side and in the evening a temperature of $39 \cdot 5^{\circ} \mathrm{C} .\left(103 \cdot 1^{\circ} \mathrm{F}\right.$.). Creasotal was ordered to be repeated, but only in half the former dose-namely, one gramme (15 grains) to be taken daily in two doses. The temperature did not fall under $38.5^{\circ} \mathrm{C} .\left(101 \cdot 3^{\circ} \mathrm{F}.\right)$, so on the next day 1.5 grammes ( 22 grains) were ordered to be taken. On the following day the temperature fell to $37 \cdot 4^{\circ} \mathrm{O} .\left(99 \cdot 3^{\circ} \mathrm{F}\right.$.) in the morning and $37 \cdot 3^{\circ} \mathrm{C}$. $\left(99 \cdot 1^{\circ} \mathrm{F}.\right)$ in the evening. The bronchial râles diminished. The parents now took it upon themselves to administer only half the amount of the creasotal that was ordered. This was followed on the next morning by an increase of the temperature to $39^{\circ} \mathrm{C}$. $\left(102.2^{\circ} \mathrm{F}^{\circ}\right.$ ), with chills. Then, finally, I returned to the first dose of two grammes ( 30 grains) daily. On the same evening the temperature fell to $37^{\circ} \mathrm{C}$. $\left(98.6^{\circ} \mathrm{F}\right.$.) and did not rise again as the creasotal was continued for five days longer in two. gramme (30-grain) doses daily.

Case 7. - This patient was 39 years old and suffered from pneumonia, with pain (stitches) in the side and chill, but nothing abnormal was heard on auscultation. In the evening there was widespread bronchial breathing over the entire middle region of the right lung and the temperature was $399^{\circ} \mathrm{C} .\left(103 \cdot 8^{\circ} \mathrm{F}\right.$ ). 10 grammes (two and a half drachms) of creasotal (Von Heyden) were taken daily in two doses. On the next morning the temperature was $38.2^{\circ} \mathrm{C} .\left(100.8^{\circ} \mathrm{F}\right.$.) The bronchial breathing had been already replaced by the "rale redux." The evening temperature was $38^{\circ} \mathrm{C}$. $\left(100 \cdot 4^{\circ} \mathrm{F}\right.$.) The temperature on the following morning was $37.1^{\circ} \mathrm{C}$. $\left(98.8^{\circ} \mathrm{F}.\right)$. The patient craved for food. The creasotal was continued in half the above dose for five days longer and recovery was complete on the sixth day.

CASE 8.-This patient was a man, 24 years old, suffering: from broncho-pneumonia which began on the twenty-first day after a probable attack of intluenza. He presented 2 marked typhoid condition with albuminuria and intense dyspnoea. There was inflammation of the right lung. The temperature was continuously above $40^{\circ} \mathrm{C} .\left(104.0^{\circ} \mathrm{F}\right.$ ): The pulse was 104; the heart-sounds were weakened. Spartein was given and was followed by injections of caftein and ergotin. There was violent delirium. Serum diagnosis on the twenty-second day of the disease gave a negative result. A pulmonary form of influenza was suspected. Four dajs later marked râles were heard. Six grammes (one and a half drachms) of creasotal (Von Heyden) were given daily. In the 24 hours following the first administration of the creasotal there was a sudden fall of the temperature to $38.7^{\circ} \mathrm{C}$. $\left(101 \cdot 6^{\circ} \mathrm{F}\right.$.). The delirium continued. On the next day 10 grammes (two and a half drachms) of creasotal were administered. The bronchial respiration over the right lung diminished, whilst new and very extensive bronchial breathing was noted over the left. On the next day the temperature was $374^{\circ} \mathrm{C} .\left(99 \cdot 3^{\circ} \mathrm{F}\right.$.); bronchial breathing had disappeared and in its place there were crepitant râles. The heart-sounds were better and the general condition was much improved. The 10 grammes (two and a half drachms) of creasotal daily were continued. The temperature did not become permanently normal till the fifteenth day of the creasotal treatment. The râles gradually disappeared under continuous and slowly diminished medication.

CASE 12.-This patient was a child, eight months old who had caught lobular broncho-pneumonia from his father, $\mathrm{He}$ was treated from the beginning with one gramme (15 grains) of creasotal daily. Apyrexia set in after 36 bours, but the auscultatory signs did not change and 30 hours later the temperature began to rise again. The dose of creasotal was increased to two grammes ( 30 grains) daily, and 30 hours later the temperature was normal and the râles bad diminished; in two days more these latter had entirely disappeared.

CASE 14.-This patient was a child, three months old, suffering from severe broncho-pneumonia. The temperature fell on the fourth day of the disease after the first dose of creasotal. There were complete apyrexia and recovery by the seventh day.

CASE 17. - This patient was a man 45 years old suffering from broncho-pneumonia. There was rapid deferrescence under creasotal and recovery was complete by the ninth day.

OASE 18.-This patient was a woman, 54 years old, who was attacked by influenza in a pulmonary form. There was apyrexia on the first day after the administration of creasotal, six grammes of which she took daily. Recovery was complete on the fourth day.

Radebeul, Germany.

Southport MEdical Soctety.-A society under the above title was constituted at a meeting held recently at the Temperance Institute, Southport. There was a good attendance of gentlemen practising in Southport, Birkdale, and district. A code of laws previously drawn up by a provisional committee was approved and the following officers were elected :-President: Dr. H. W. Vernon. President-elect: Dr. Robert Harris. Vice-President: Dr. Pinkerton. Treasurer: Dr. Baildon. Secretary : Mr. R. M. Littler (29, Hawksheadstreet). Committee: Mr. Reinhardt Anderson, Dr. Ashworth, Dr. Barrett, Mr. Baines, Mr. A. J. Popert, and Dr. G. C. Walker, sen. The first meeting of the session will be held in the Albany Galleries on Wednesday, Oct. 11th, whed Sir William Mitehell Banks will deliver an address. 